\title{
Farmers' Seed Systems and Management Practices Determine Pearl Millet Genetic Diversity Patterns in Semiarid Regions of India
}

\author{
K. vom Brocke, A. Christinck, E. Weltzien R., T. Presterl, and H. H. Geiger*
}

\begin{abstract}
Pearl millet [Pennisetum glaucum (L.) R. Br.] landraces provide nutritional quality and security under the harsh environmental conditions of Rajasthan, India. Using amplified fragment length polymorphism (AFLP), this study investigated pearl millet genetic diversity patterns and related the results to farmers' local knowledge and seed systems. Thirty-nine cultivars were assessed: 14 farmer landraces from western Rajasthan, 13 farmer landraces from eastern Rajasthan, and 12 control cultivars. Shannons' information index for western $(H=$ $0.34)$ and eastern $(H=0.32)$ Rajasthan landraces was up to $14 \%$ higher than in composite-based improved cultivars. Analysis of molecular variance (AMOVA) revealed that variation within landrace populations was much higher than between regional samples. In the west, intra-village variation was higher than inter-village variation. In the east, variation between landrace groups bearing a specific name was higher than intra-group variation. Gene flow, inferred from genetic distances between populations, was used as an indicator for seed exchange between farmers. In western Rajasthan, seed exchange appears to be especially dynamic, as gene flow was greater than $N_{\mathrm{e}} \mathrm{m}=$ 25 among most of its populations. Farmers' knowledge of local cultivars and seed systems was, for the most part, supported by the AFLP analysis. These results are relevant for in situ maintenance and breeding strategies with a view to improving traditional cultivars, specifically performance and yielding stability.
\end{abstract}

$\mathrm{N}$ ATURAL OCCURRENCES, as well as human activities, can lead to phenotypic crop diversity within a given production system (e.g., Sperling et al., 1993; Bellon and Brush, 1994; Louette et al., 1997; Weltzien et al., 1998). However, relatively few studies have dealt with the effects of farmers' seed and diversity management at a molecular level. To simulate the evolution of traditional sorghum cultivars in Burkina Faso, Ollitrault et al. (1997), using isozyme data, analyzed the effect of farmer selection. To explain the high level of intrapopulation diversity, the authors suggested that farmer selection might be in favor of heterzygotes. Busso et al. (2000), using AFLP markers, suggested that the traditional names of pearl millet landraces used in West

K. vom Brocke, Centre de Coopération Internationale en Recherche Agronomique pour le Développement (CIRAD) 01 BP. 596, Ouagadougou 01, Burkina Faso; A. Christinck, Univ. of Hohenheim, 430A Institute for Social Sciences of the Agricultural Sector, Dep. of Communication and Extension, D-70593 Stuttgart, Germany; E. Weltzien R., International Crops Research Institute for the Semi-Arid Tropics (ICRISAT), B.P. 320, Bamako, Mali; T. Presterl and H.H. Geiger, Univ. of Hohenheim, 350b Institute of Plant Breeding, Seed Science and Population Genetics, D-70593 Stuttgart, Germany. Funding for this study was provided by the German Ministry for Economic Cooperation and Development (BMZ) through the German Society for Technical Cooperation (GTZ) (Grant No. 96.7860.8-001.00). Received 25 March 2002.*Corresponding author (geigerhh@unihohenheim.de)

Published in Crop Sci. 43:1680-1689 (2003).

(C) Crop Science Society of America

677 S. Segoe Rd., Madison, WI 53711 USA
Africa do not adequately reflect the landraces' discrete genetic identities.

To understand the dynamics of local crop diversity, an interdisciplinary approach is required in which the disparate elements of population genetics, environmental and social aspects, farmers' own local knowledge, and the circumstances of their seed systems, are all integrated (Brown, 2000). By this approach, effective in situ conservation strategies can be developed that will prevent loss of diversity in farmers' fields and help sustain the processes of evolution, namely, the adaptation of crops to their changing environments (Brush, 1991).

Pearl millet is a hermaphroditic species with strong protogyny and cross pollination of up to $82 \%$ (Burton, 1974). Leuck and Burton (1966) have shown that wind is the main factor responsible for pollen dispersal. Pearl millet is the staple food of the semiarid state of Rajasthan in northwest India. The adoption rate of improved cultivars in Rajasthan has been relatively slow, particularly in the dry western region which lies in the transition zone of the Thar Desert (Kelley et al., 1996; Tripp and Pal, 1998). Farmers in this region prefer to rely on landraces specifically adapted to the area's harsh agronomic and climatic conditions (Christinck et al., 2000). These landraces possess superior nutritional quality as well as higher fodder yield under severe conditions (Kelley et al., 1996).

Pearl millet landraces in western Rajasthan are characterized by early maturity, a height of 1.5 to $2.5 \mathrm{~m}$, thin stems, and strong asynchronous tillering. Appa Rao et al. (1986) divided these western Rajasthan landraces into three morphological types: the Chadi landrace, which is the most prevalent; the Barmer landrace, characterized by a high diversity of morphological traits; and a desert-type landrace with shattering spikelets and persistence of glumes on the seeds, and which is predominantly found in the desert areas of Jodhpur and Jaisalmer.

As one moves toward the east and rainfall increases, the use of improved cultivars, mostly single-cross hybrids, also increases (Tripp and Pal, 1998). In an earlier study, four late-maturing landraces were identified in the central and eastern parts of Rajasthan: Jakharana, Karauli, Gullisita, and Sulkhania (Appa Rao et al., 1986). Each is morphologically distinct from the other and named after the village of origin. All generally require 3.5 to 4.5 mo to mature, which is markedly longer

Abbreviations: AFLP, amplified fragment length polymorphism; ALR, African landrace; AMOVA, analysis of molecular variance; ERL, eastern Rajasthan landrace; FS, full-sib family; HY, hybrid; OPC, open pollinated cultivar; PRA, participatory rural appraisal; UPGMA, unweighted pair-group method of arithmetic averages; WRL, western Rajasthan landrace 
Table 1. Groups and description of materials used as controls.

\begin{tabular}{lll}
\hline Cultivar group & Population & \\
\hline Full-sib family populations & FS1 & Bulked full-sib families from a "pure" landrace \\
& FS2 & Landraces diversified by frequent introgression of modern cultivars. Farmer performs panicle selection \\
Open-pollinated cultivars & FS3 & Landraces diversified by frequent introgression of modern cultivars. Farmer performs winnowing method \\
& OPC1 & Rajasthan Composite Bajra (RCB-IC 911) \\
& OPC2 & World composite Cycle (WC-C 75) \\
OPC3 & CZ-IC 923 \\
& ALR1 & Ex Bornu, landrace from northern Nigeria \\
Hybrids & ALR2 & Composite International de Tarna (CIVT), Niger \\
& HY1 & BK-560 \\
& HY2 & MH-179 \\
& HY3 & HHB 67 \\
& HY4 & MH 169 (= Pusa 23) \\
\hline
\end{tabular}

than the landraces from western Rajasthan or the commercially available improved cultivars.

Different environmental, socioeconomic and cultural factors may contribute to the diversification of landraces (Weltzien et al., 1998). Yet no comprehensive diversity analysis has been performed at the molecular level. Therefore, a new project was initiated with the aim of describing farmers' seed management and crop improvement activities in terms of diversity patterns and molecular marker analysis. This was thought best approached through a combination of population genetics and social science. The social science part involved the investigation of farmers' classification system of pearl millet cultivars, their seed management and traditional seed markets (Christinck, 2002). In 1997, pearl millet landraces from western and eastern Rajasthan were collected by using a participatory approach for the purpose of the present study (Christinck et al., 2000); this approach is briefly explained in the section "Collection and Documentation." The molecular analysis of this germplasm is the focus of this paper. The results obtained by social science methods, however, will also be referred to in the body of this study, as these results are integral to the interpretation of the molecular marker results.

The present study is a collaboration between the International Crops Research Institute for the Semi-Arid Tropics (ICRISAT), the National Bureau for Plant Genetic Resources (NBPGR), India, and the University of Hohenheim, Germany. The objectives of this study were to investigate genetic diversity on the basis of AFLP in pearl millet landraces in Rajasthan at regional, village, and farm levels; and to relate these results to environmental factors, farmers' seed management systems, and local production practices. Results are discussed in regard to in situ maintenance and breeding strategies for improving the performance of traditional pearl millet cultivars.

\section{MATERIALS AND METHODS}

\section{Genetic Materials}

Thirty-nine pearl millet cultivars were used in this study. Twenty-seven were samples of farmers' pearl millet landraces, each comprising 19 to 30 panicles randomly collected from fields or threshing grounds in Rajasthan. The remaining 12 were control cultivars (Table 1). Nine control cultivars were provided by ICRISAT's gene bank, which were representative of cultivars grown commercially or which are frequently used in Indian pearl millet breeding programs. The remaining cultivars were derived from three farmer-generated populations in the village of Aagolai in the western Rajasthan district of Jodhpur (Vom Brocke et al., 2002). Each consisted of about 90 full-sib progenies. Two of the latter populations had been actively modified by farmers through introgression of various improved cultivars. All conscious introgression had been avoided in the third.

The 39 cultivars were assorted to six groups: two landrace groups representing western (WLR) and eastern Rajasthan (ELR), and four control cultivar groups comprising three populations of full-sib progenies (FS), two African landraces (ALR), three improved open-pollinated cultivars (OPC), and four single-cross hybrids (HY), respectively (Table 2 ).

\section{Study Area}

Rajasthan is a predominantly semiarid region traversed by the Thar Desert, which also extends into neighboring Pakistan. A low mountain range (Aravali Range) divides the state into two distinct geographic areas (Fig. 1). These mountains keep western Rajasthan in a rain shadow that only allows an annual rainfall ranging from 250 to $350 \mathrm{~mm}$. Soils of this region are predominantly sandy and unproductive, with more than $50 \%$ of the area covered by sand dunes (Chouhan, 1993). Pearl millet is grown as a monsoon crop in western Rajasthan, usually without irrigation and usually in mixed cropping with various legumes and cucurbits. Rainfall is more plentiful east of the Aravalis, ranging from 550 up to $800 \mathrm{~mm}$ annually. Soils are also more fertile due to a higher silt and clay content. Irrigation facilities are more widely available in the east where also a second crop can be grown during the dry winter season.

Table 2. Population sample size $(\mathbf{N})$, Shannon's information index $\left(\mathbf{H}_{\text {group }}\right)$ ( \pm standard error) and percentage of polymorphic markers $(\mathrm{PM} \%)$ averaged across populations from six pearl millet cultivar groups. In brackets group ranges.

\begin{tabular}{|c|c|c|c|}
\hline Cultivar group & $N$ & $\mathbf{H}_{\text {group }}$ & $P M \%$ \\
\hline Western Rajasthan landraces (WLR) & 22-34 & $0.337 \pm 0.004(0.315-0.359)$ & $76.8(72.8-83.8)$ \\
\hline Eastern Rajasthan landraces (ELR) & 19-31 & $0.317 \pm 0.005(0.293-0.339)$ & $69.5(59.6-76.2)$ \\
\hline Full-sib families (FS) & 87-99 & $0.357 \pm 0.009(0.349-0.367)$ & $88.8(86.0-92.8)$ \\
\hline Open-pollinated cultivars (OPC) & 28-30 & $0.287 \pm 0.010(0.256-0.312)$ & $64.5(54.9-70.2)$ \\
\hline African landraces (ALR) & 30 & $0.258 \pm 0.012(0.276-0.241)$ & $56.4(52.3-60.4)$ \\
\hline Hybrids (HY) & 4-5 & $0.118 \pm 0.007(0.030-0.180)$ & $19.4(5.1-28.9)$ \\
\hline
\end{tabular}




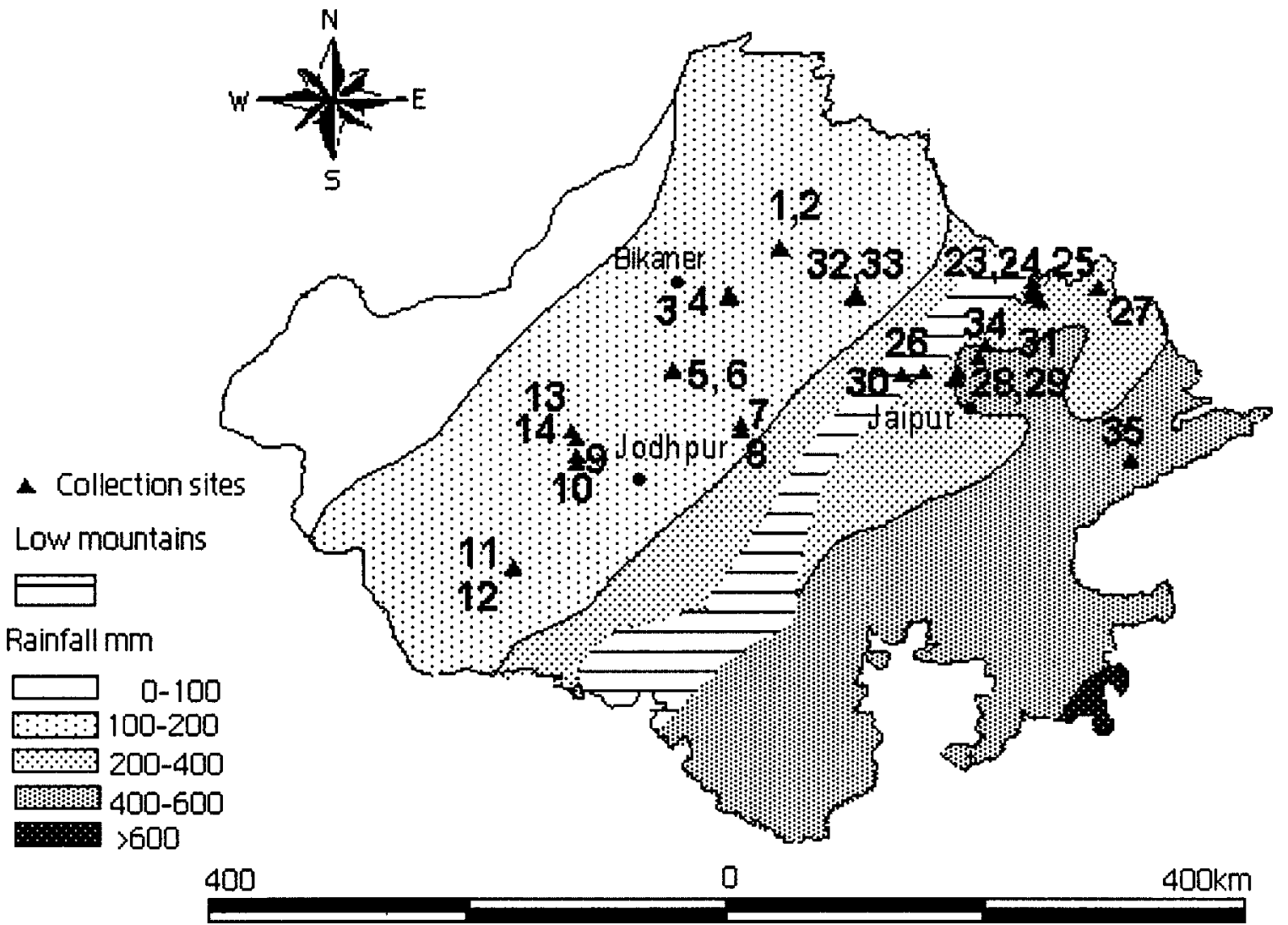

Fig. 1. Map of Rajasthan. Numbers identify collection sites and population samples WLR1-WLR14 and ELR23-ELR35.

\section{Collection and Documentation}

Interviews and collections were performed in the main pearl millet growing areas of Rajasthan in September and October of 1997. The collection team consisted of an agricultural social scientist, a socio-economist and a translator. The collection strategy was based on the social science approach of "Participatory Rural Appraisal" (PRA) (Schönhuth and Kievelitz, 1994). The collection and communication methodology is described by Christinck et al. (2000). The main criteria for choosing a landrace sample were: (i) the absence of conscious introgression of improved material and, (ii) that farmers considered the landrace to be a pure or typical landrace.

Landrace samples were collected from 10 districts across Rajasthan. In the west, two to four villages per district were chosen as sample sites. In most cases, samples were collected from two different farmer households within the one village. The sampled districts were Churu (samples WLR1 and WLR2), Bikaner (WLR3, WLR4, WLR5, and WLR6), Jodhpur (WLR7, WLR8, WLR13, and WLR14) and Barmer (WLR9, WLR10, WLR11, and WLR12). Although farmers in the Bikaner district grow almost exclusively pure landraces, it is generally difficult to find genuinely pure landrace material in western Rajasthan, especially in the Jodhpur district, because farmers usually mix small quantities of improved cultivar seed into their own landrace seed. Most of the farmers in western Rajasthan who provided seed samples described their seed as home production. Other farmers obtained their seed from another farmer within their own village or from the local market.

In eastern Rajasthan, landraces named after their village of origin were collected from Jakharana (ELR23), Gowalda (ELR28), Dhodsar (ELR27 and ELR28), Mandota (ELR31), Sulkhania (ELR32 and ELR33), Gunawata (ELR34), and
Karauli (ELR35). These will be referred to as original landraces, unless found outside their village of origin, in which case they will be referred to as introduced landraces. The latter includes introduced Jakharana landrace (ELR24, ELR25, and ELR26) and introduced Dhodsar landrace (ELR30).

\section{DNA Extraction and Amplification}

One seedling per panicle per population was grown in a pot in a greenhouse for about $1 \mathrm{wk}$ or until 15 to $30 \mathrm{mg}$ fresh leaf tissue was available. Genomic DNA was extracted from each seedling by Keygene, Inc. AFLP analyses were also conducted by Keygene, Inc., in accordance with the protocol of Vos et al. (1995). The DNA was digested using four PstI/ Mse I primer combinations with $+2 /+3$ selective nucleotides: $P s t \mathrm{I}+\mathrm{AA}$ and $M s e \mathrm{I}+\mathrm{CGA} ; \quad P s t \mathrm{I}+\mathrm{AC}$ and $M s e \mathrm{I}+\mathrm{ATT}$; $P s t \mathrm{I}+\mathrm{AG}$ and $M s e \mathrm{I}+\mathrm{CAG} ; P s t \mathrm{I}+\mathrm{AG}$ and $M s e \mathrm{I}+\mathrm{CTG}$. Information on suitability of primer combinations was provided by Dr. X. Qi, John Innes Centre, Norwich, U.K.

\section{Data Analysis}

AFLP bands were scored for presence (1) or absence (0) for a total of 1064 individual plants of the 39 pearl millet cultivars. Shannon's information index (Kremer et al., 1998) was used for describing the diversity within populations, as revealed by the AFLP markers. The index is computed as:

$$
H=-\sum_{i=1}^{n}\left[f_{i} \ln f_{i}+\left(1-f_{i}\right) \ln \left(1-f_{i}\right)\right] / n
$$

where $f_{i}$ is the frequency of the AFLP band at the $i$ th locus in the respective population and $n$ is the total number of marker loci $(n=235)$. Monomorphic markers were not ex- 
cluded from the data set. The program POPGEN ver. 1.31 (Yeh et al., 1999) was used for the calculations.

Analysis of molecular variance based on squared Euclidean distances (AMOVA, Excoffier et al., 1992) was performed by means of the software package ARLEQUIN (vers. 1.1), developed by Schneider et al. (1997). It was applied to a hierarchical linear model with random effects for cultivar groups $(a)$, populations within cultivar groups $(b)$, and individuals within populations $(c)$. Effects are assumed to be additive, uncorrelated, and to have the associated variance components $\sigma_{a}^{2}, \sigma_{b}^{2}, \sigma_{c}^{2}$, respectively (Schneider et al., 1997). Besides variance components, ARLEQUIN also calculates the $\Phi$-statistics [analogous to Wright's (1951) $F$-statistics], the most important of which, $\Phi_{S T}$ describes the genetic differentiation between populations. It is defined by

$$
\Phi_{S T}=\frac{\sigma_{a}^{2}+\sigma_{b}^{2}}{\sigma^{2}}
$$

with $\sigma^{2}=\sigma_{a}^{2}+\sigma_{b}^{2}+\sigma_{c}^{2}$. Two regional AMOVAs, one for western, the other for eastern Rajasthan landraces, were also calculated, again in regard to a hierarchical random effects model. In the case of western Rajasthan, random effects were for villages, landraces within villages, and individuals within landraces. In the case of eastern Rajasthan, random effects were for landraces bearing the same name, landraces within name groups, and individuals within landraces. AMOVA tests for significance of variance components were based on permutational methods as described by Excoffier et al. (1992).

Genetic distances $\left(\Phi_{S T}\right.$ values) among populations revealed by AFLP polymorphism were visualized by a dendrogram using the unweighted pair-group method of arithmetic averages (UPGMA) of the NTSYSpc 2.02 program (Rohlf, 1993).

Gene flow $\left(N_{\mathrm{e}} \mathrm{m}\right)$ between populations, based on $\Phi_{\mathrm{ST}}$ values, was calculated according to Slatkin and Barton (1989): $N_{\mathrm{e}} \mathrm{m}=$ $0.25\left(1-\Phi_{\mathrm{ST}}\right) / \Phi_{\mathrm{ST}}$, where $N_{\mathrm{e}}$ is the effective population size and $m$ the average migration rate. Gene flow estimates were related to geographical distances, calculated from the coordinates of the collection sites. For this purpose, the data from western and eastern Rajasthan were analyzed separately. Logarithms to the base of 10 of both the gene flow and the geographic distance measures were used for the analyses (Slatkin, 1993; Parzies, 2000).

\section{RESULTS AFLP Analysis}

The four primer combinations used to analyze the 1064 individual plants generated a total of 235 polymorphic markers with 52 to 63 markers per primer combination. AFLP polymorphism calculated as percent polymorphic loci in the 39 cultivars ranged from $92 \%$ in the full-sib population FS2 to less than $20 \%$ in the single- cross hybrids. Except for the hybrid group, all other group averages for percentage of polymorphic markers were higher than $50 \%$, with the full-sib populations reaching nearly $90 \%$ (Table 2 ). A slight tendency toward higher polymorphism was found in populations with larger sample size.

\section{Marker-Based Diversity and Partitioning of Diversity}

Shannon's information index $(H)$ was calculated for cultivar groups and populations from the 235 AFLP markers. The highest average diversities were estimated for the full-sib group (0.36) and the western Rajasthan landraces group (0.34). Estimates for the eastern Rajasthan landraces and improved open-pollinated cultivars were slightly lower. Compared to the full-sib group, the African landraces showed on average $25 \%$ less markerbased diversity, the hybrid group almost $70 \%$ less (Table 2).

The AMOVA that included all 39 cultivars showed highly significant genetic differences for all sources of variation. Within-population diversity explained most of the genetic diversity ( $88 \%$ ). Variation among populations within cultivar groups was $2 \%$ lower than variation among cultivar groups (Table 3 ). Three percent of the total variation was due to differences between the western and eastern Rajasthan groups (data not shown). In the eastern Rajasthan group, variation was significant for all sources of variation. Variation among name groups was three times higher than the variation among landraces within name groups. Both these sources explained only $7 \%$ of the total variation (Table 3 ). The AMOVA revealed no significant variation among villages in western Rajasthan. Within villages, variation among landrace populations was low but significant $(1.1 \%)$. Diversity within western landrace populations was even higher than in eastern landrace populations (98\%) (Table 3).

\section{Genetic Distance between Farmers' Populations}

The UPGMA dendrogram of the 39 cultivars illustrated that the western and eastern Rajasthan landraces form two subgroups, both being different from the openpollinated cultivars and the full-sib populations FS2 and FS3 (Fig. 2). Genetic distances ( $\Phi_{S T}$ values) among populations within the western and eastern landrace groups were all below $\Phi_{S T}=0.05$. The closest genetic relationship was measured among landrace populations of the

Table 3. Overall (a) and regional (b, c) analyses of molecular variance (AMOVA) of pearl millet samples from western and eastern Rajasthan based on 235 AFLP markers.

\begin{tabular}{|c|c|c|c|c|}
\hline Type of AMOVA & Source of variation & df & Variance component & Percent variation \\
\hline \multirow[t]{3}{*}{ a Overall } & Among cultivar groups & 5 & $1.58 * *$ & 6.65 \\
\hline & Among populations within cultivar groups & 33 & $1.17 * *$ & 4.91 \\
\hline & Individuals within populations & 1143 & $20.96 * *$ & 88.43 \\
\hline \multirow[t]{3}{*}{ b Western Rajasthan } & Among villages & 6 & 0.04 & 0.15 \\
\hline & Landraces within villages & 7 & $0.25 * *$ & 1.11 \\
\hline & Individuals within landraces & 401 & $22.62 * *$ & 98.74 \\
\hline \multirow[t]{3}{*}{ c Eastern Rajasthan } & Among name groups & 6 & $\mathbf{1 . 0 3}^{* * *}$ & 4.89 \\
\hline & Landraces within name groups & 6 & $0.34 * *$ & 1.63 \\
\hline & Individuals within landraces & 303 & $19.62 * *$ & 93.48 \\
\hline
\end{tabular}

** Significant at the 0.01 probability level. 


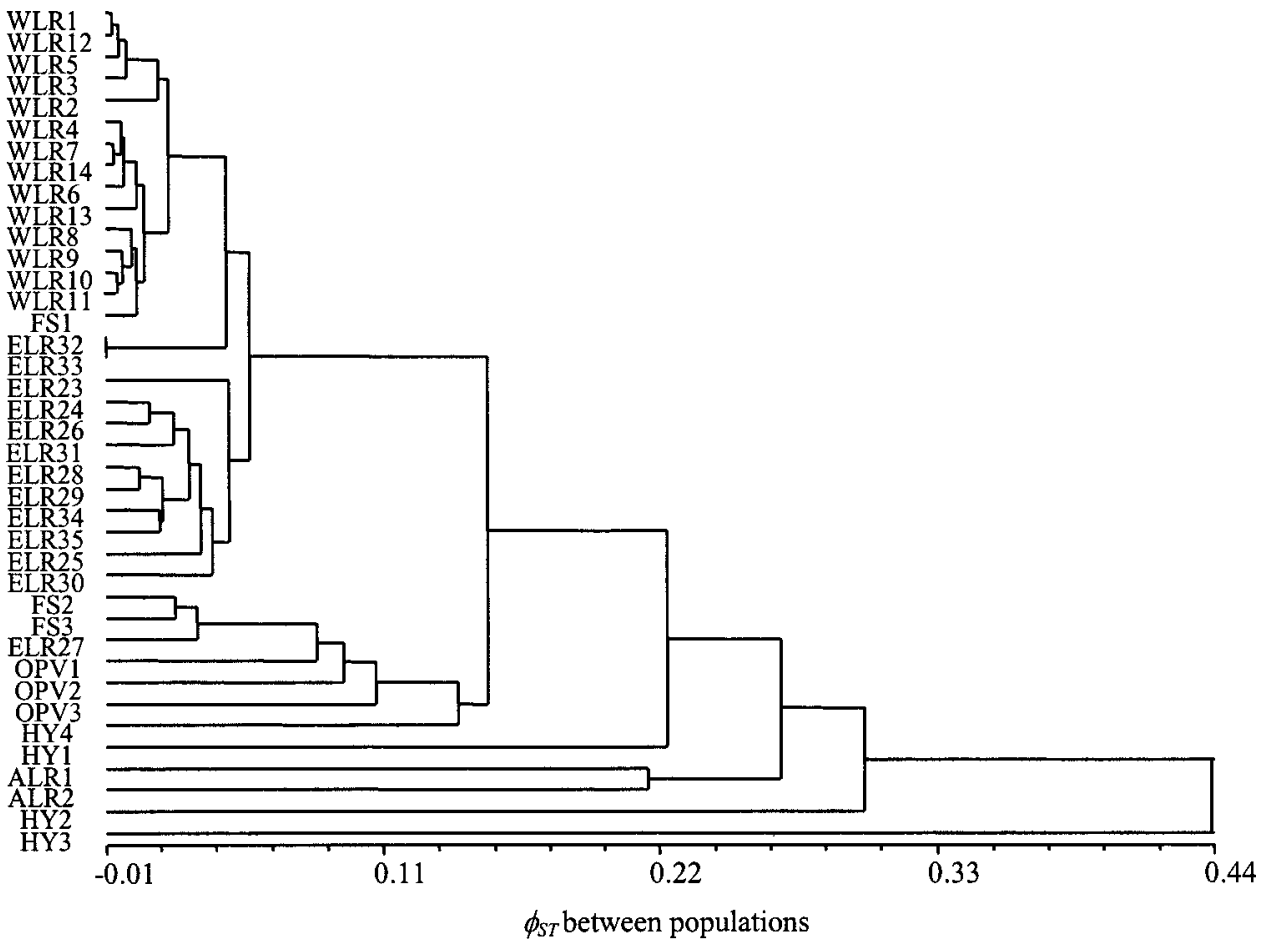

Fig. 2. UPGMA dendrogram illustrating the genetic distances ( $\phi_{S T}$ values) among 39 pearl millet cultivars estimated from 235 AFLP markers. Cultivars consisted of landraces from western (WLR) and eastern (ELR) Rajasthan, full-sib family populations from western Rajasthan (FS), improved open-pollinated cultivars (OPC), African landraces (ALR), and Hybrids (HY).

western group. The eastern Rajasthan subgroup showed higher genetic distances among populations compared with the western subgroup. Even though the full-sib populations FS2 and FS3 are based on western Rajasthan landrace material, they cluster to a separate subgroup consisting of the eastern Rajasthan landrace ELR27, the open-pollinated cultivars and the hybrid HY4. Genetic distances between cultivars in this subgroup range between 0.03 and 0.13 . The African landraces form two groups that separate from the aforementioned subgroups. Hybrids HY1-HY3 show the highest genetic distances to the landrace populations and to each other.

In the case of certain populations, clustering did not correspond to their breeding history. For instance, the Sulkhania landraces (ELR32, ELR33) diverge from both regional groups and instead show slightly more similarity with the western landraces. The Gowalda landrace (ELR27) from eastern Rajasthan is more similar to the improved open-pollinated cultivars than to either of the landrace groups.

\section{Gene Flow}

There was no significant relationship between gene flow and geographical distance in western Rajasthan (Fig. 3). Gene flow in this group was mostly greater than 25 migrants per generation, which was in the lower range of the sample size analyzed per population. Values of this magnitude were observed in about one-third of the western Rajasthan landraces, and even between populations separated by a distance of more than 300 $\mathrm{km}$. In regard to landraces originating from the same village, particularly high gene flow was found for population pair WLR9/10. For most other landraces originating from the same or a neighboring village (WLR1/2, WLR5/6, WLR7/8, WLR11/12, WLR13/14), gene flow was estimated between $N_{\mathrm{e}} \mathrm{m}=10.0$ and 25.0.

Estimates of gene flow among eastern Rajasthan landraces were generally lower than those of western Rajasthan (Fig. 4). Low gene flow $\left(N_{\mathrm{e}} \mathrm{m}<1\right)$ was observed between the Gowalda landrace (ELR27) and all other landrace samples collected in eastern Rajasthan, as well as between Sulkhania landraces (ELR32 and ELR33) and all other samples. Values for gene flow between different types of landrace, such as Karauli (ELR35) and Gunawata (ELR34), ranged from 5 to 20.

Gene flow between landrace samples bearing the same local name ranged from 6 to 20 for Jakharana and 10 and 23 for Dhodsar. The lowest gene flow between the original Jakharana landrace and an introduced Jakharana landrace was estimated for the sample ELR25 collected in a village $2 \mathrm{~km}$ away from the Jakharana village. The highest gene flow was estimated between the original Jakharana and sample ELR26, even though these sample sites were located more than $100 \mathrm{~km}$ apart. Both samples from the village of Dhodsar (ELR28, ELR29) as well as from the Sulkhania village (ELR32 and ELR33) displayed gene flow greater than 30.0.

\section{DISCUSSION}

\section{Genetic Diversity in Pearl Millet Materials}

AFLP markers are particularly useful and effective for mapping and fingerprinting, as well as for analyzing 


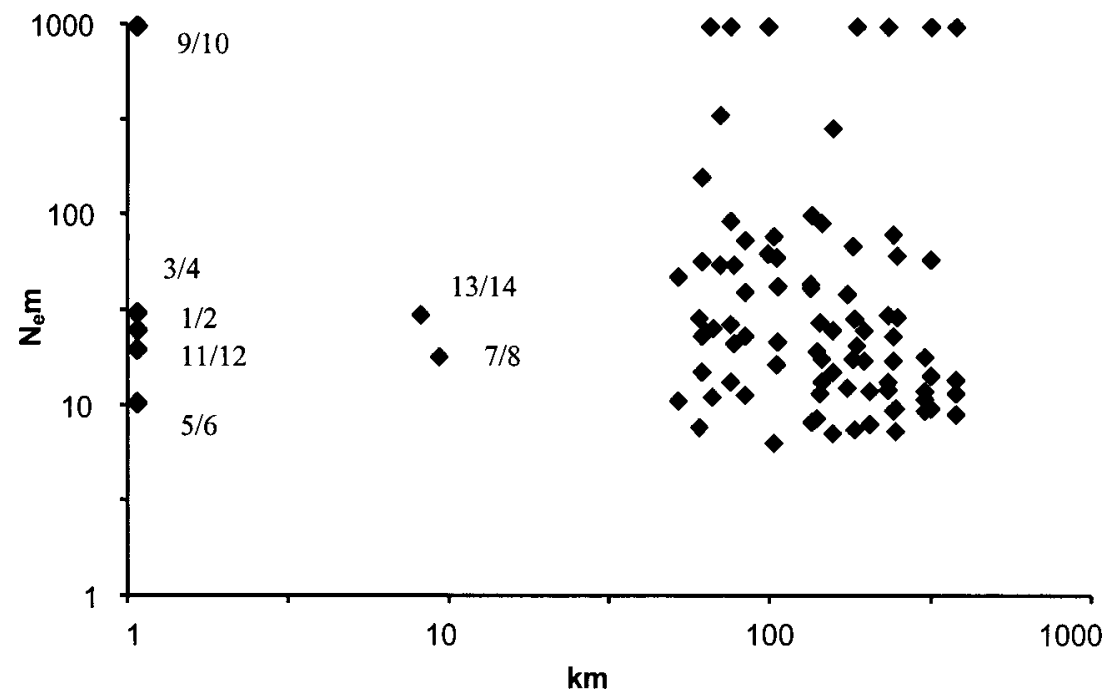

Fig. 3. Relationship between gene flow $\left(N_{\mathrm{e}} \mathrm{m}\right.$ estimates) and geographic distance $(\mathrm{km})$ among western Rajasthan landraces. Logarithmic scales (to the basis 10) are used for both variables.

genetic distance (e.g., Maughan et al., 1996; Karp et al., 1998; Barrett and Kidwell, 1998). In the present study, the high number of polymorphic DNA fragments (a total of 235 averaging 60 per primer combination) were found to be highly suitable for evaluating genetic diversity, particularly in regard to genetic distances, and even between closely related populations. Nevertheless, AFLPs are a dominant marker system which does not allow for a proper genetic interpretation. Therefore, diversity analysis in the present study could not be based on allele frequencies but had to refer to marker band frequencies. The effectiveness of AFLP markers for classifying pearl millet landrace populations has also been emphasized by Busso et al. (2000). The authors described the AFLP marker system as the appropriate approach where full sets of microsatellite markers did not exist, as was the case in the present study.

The landraces from western and eastern Rajasthan form two close clusters: the early-maturing, strong-tillering, short-to-medium-length pearl millet landrace types of western Rajasthan; and the tall, mainly late-maturing, higher-yielding types of eastern Rajasthan. A cluster analysis based on morphological and developmental traits performed by Vyas (1987) on Rajasthan landraces revealed a similar clustering. The AFLP-based dendrogram indicates that Sulkhania is an intermediate type between the western and eastern landraces. This is in agreement with the observations of farmers. The Sulkhania landrace is grown in a transition zone between the dry west and the more favorable east. Morphologically, Sulkhania resembles the eastern landrace types (Appa Rao et al., 1986), combined with specific attributes typical for the western landraces such as a high-tillering ability and tolerance to high temperatures (Christinck, 2002). The Gowalda landrace was found to be more similar to the control cultivars than to other landrace types of the eastern group. This may be due to a relatively high degree of unintended introgression resulting from the widespread use of improved cultivars in the Gowalda village, which may also explain the morpho-

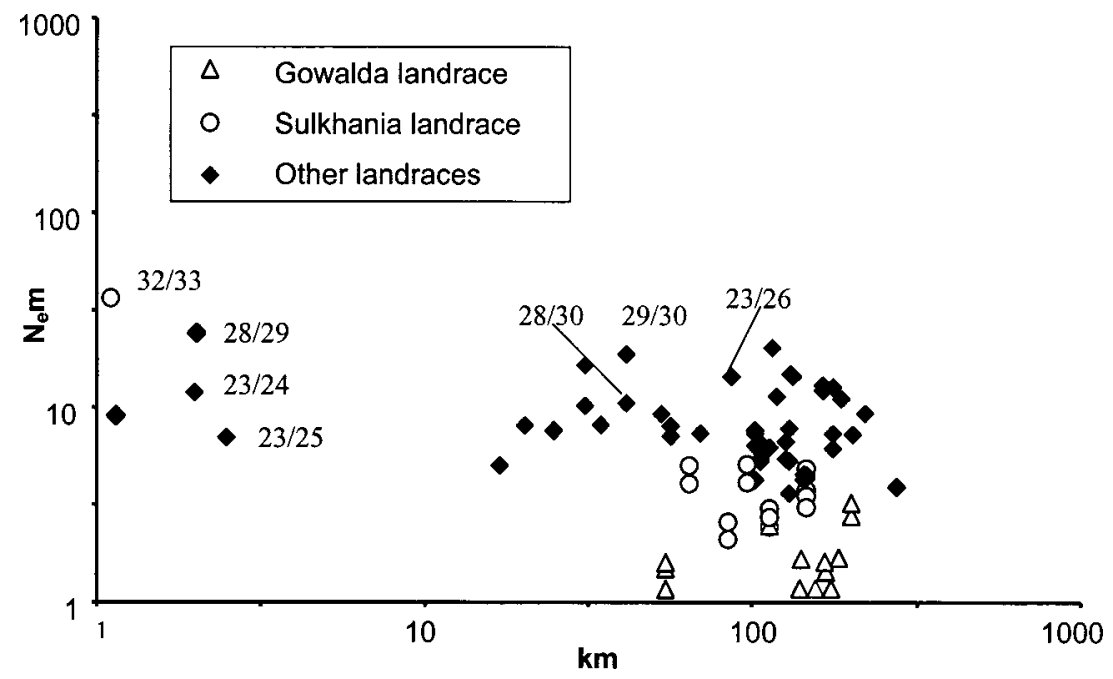

Fig. 4. Relationship between gene flow ( $N_{\mathrm{e}} \mathrm{m}$ estimates) and geographic distance $(\mathrm{km})$ among eastern Rajasthan landraces. Logarithmic scales (to the basis 10) are used for both variables. 
logical changes in the Gowalda landrace as observed by farmers. Full-sib populations FS2 and FS3 from Jodhpur district formed a cluster with the open-pollinated cultivars OPC1-OPC3. The clustering of both FS populations with the open-pollinated cultivars, rather than with the western Rajasthan landrace group, indicates that introgression of improved cultivar material is an effective method for increasing genetic dissimilarity between landrace populations. Both FS populations were produced from farmer grain stocks that were diversified by introgression of improved cultivars (Vom Brocke et al., 2002).

Results show that most of the AFLP variation is caused by differences between individuals within populations. This is in agreement with the results of other studies in cross-pollinating crops; e.g., Tostain (1994) identified three major maturity groups in West African pearl millet landraces by means of isozyme markers. The diversity among these three groups was $4.5 \%$, while $90 \%$ of total diversity resided within the groups. Variability within populations can function as a buffer which enables a population to respond to extremely variable environmental conditions (Allard and Bradshaw, 1964).

Landraces represent extremely diverse and dynamic gene pools that have evolved over time through farmer activities and natural selection (Hawtin et al., 1997). In the present study, AFLP polymorphism indicates that genetic diversity of pearl millet landraces was even higher than in composite-based improved cultivars, and almost three times higher than in hybrid cultivars. The latter were, on average, more heterogeneous than expected which might be due to not fully inbred parent lines. Nevo et al. (1998) pointed out that high indices for gene diversity, as indicated by RAPD polymorphism in wild barley (Hordeum spontaneum K. Koch), are associated with highly stressful environments. Growing conditions in western Rajasthan are more severe than those in eastern Rajasthan. However, AFLP polymorphism showed that regional agroclimatic factors had only a small effect on the average genetic diversity of landraces. Shannon's information indices estimated for the western region were only slightly greater than for eastern Rajasthan (Table 2).

Unintentional introgression may be a possible explanation for the somewhat higher diversity indices of some landraces in the villages of the Jodhpur and Barmer districts (data not shown) where cultivation of commercial cultivars is relatively common. Diversity of landrace samples collected in these districts was of a similar magnitude as that of the FS2 and FS3 populations generated by farmers implementing targeted introgression of improved cultivar germplasm.

\section{Possible Factors Shaping Pearl Millet Diversity Patterns in Rajasthan}

According to the farmers' perception, all western Rajasthan landraces are of the same kind (Christinck, 2002). They believe that phenotypic variation of the landrace is determined through environmental conditions, especially soil conditions. If pearl millet from a village is grown elsewhere for more than two seasons, that pearl millet will undergo morphological changes and adapt to the new environment. Conversely, any other landrace introduced into the village will eventually develop the typical characteristics of that village's pearl millet, e.g., "golden" grain color or a certain sweet taste (Christinck, 2002). Therefore, a solely morphological classification, as suggested by Appa Rao et al. (1986), does not correspond with farmers' concepts of a cultivar.

The results of molecular marker analyses revealed a strong similarity among the western Rajasthan landraces, which is in agreement with the aforementioned farmer concept. Samples collected from different villages in western Rajasthan are almost identical (Fig. 2). It may be argued that the populations are not isolated and their habitats are not sufficiently divergent to allow disruptive selection pressures that would otherwise lead to genetic differentiation over time. Seed loss due to extreme drought is not uncommon for this region. If seed is not available in sufficient quantity from fellow villagers, farmers purchase food grain from local markets for use as seed, or they ask relatives residing in other villages, which may have been less affected by the drought. Furthermore, it is a common practice that farmers pool seed lots of 1 to $2 \mathrm{~kg}$ each from various sources in times of seed scarcity (Christinck, 2002). Given these facts, it cannot be expected that landraces will differ appreciably from one village to the next.

No relation was found to exist between gene flow and geographic distance in western Rajasthan. Obviously this diversity pattern does not follow the isolation-bydistance model proposed by Slatkin (1993) for natural plant populations. It seems that seed exchange of pearl millet is not effectively limited by geographical distance in western Rajasthan, as is the opposite case in northern Syria where different landrace samples of barley (Hordeum vulgare L.) were evaluated (Parzies, 2000). It should be noted, though, that besides the seed exchange system in northern Syria being largely limited to local areas, barley is a strongly inbreeding species.

Perhaps different farmer management strategies as well as the seed source and soil conditions contribute to the differentiation of populations within a village. For example, one-third of those western Rajasthan farmers who provided seed samples for the present study reported that they selected individual panicles for use as seed grain. The other two-thirds implemented winnowing or grading for separating preferred seed grain (unpublished data). However, variation between samples within villages explained only about $1 \%$ of the total variation, which implies that the above factors hardly affect the genetic patterns of diversity. On the other hand, the significance $(P=0.01)$ of this source of molecular variance indicates that differentiating factors do exist. For example, inter-population distance may be greater if the two population samples originate from seed purchased at different market places, as was the case with the sample pairs WLR7/WLR8 and WLR11/ WLR12. Indeed, these particular population pairs revealed a slightly lower gene flow in comparison to other populations sampled within a same village. The win- 
nowing and panicle selection methods both seek the same objective, namely, to increase seed vigor. A factor that may contribute to the similarity of landraces within a village is the traditional custom of sharing seed between neighbors if stocks are low. This is practiced by those farmers who provided samples WLR1, WLR3, WLR4, and WLR10.

In contrast to the "one-landrace" concept of western Rajasthan farmers, farmers in eastern Rajasthan clearly differentiate between individual agromorphological landrace types, which are commonly named after their village of origin (Christinck, 2002). They attribute these differences to environmental phenomena at the site of origin. The farmers report that their landraces have been in existence for several hundred years. To preserve the ideotype of their specific landrace, these farmers try to avoid any form of diversification. Eight out of the 13 farmers who provided samples for the present study in eastern Rajasthan use panicle selection (unpublished data). Another seed-improvement method practiced by farmers of this region involves the interchange of seed within the same village every 3 to 5 yr (Christinck, 2002). As revealed by AMOVA, variation among landraces grouped by their name was greater than variation among populations within those name groups (Table 3). This pattern of diversity supports farmers' claims of trying to keep their landrace ideotype unique.

Seven villages in eastern Rajasthan were identified as being particularly important to the informal seed market. The landraces originating from the villages Jakharana, Dhodsar, Gunawata, and Karauli in particular are in strong demand at the local seed markets. Farmers in these villages sell between 100 and $2400 \mathrm{~kg}$ of seed per year, including to farmers more than 200 $\mathrm{km}$ away (Christinck, 2002). Yet the moderately positive correlation between geographic distance and gene flow in Fig. 4 of $r=0.40(P=0.01)$ implies that seed markets for specific landrace types are geographically restricted. The correlation between gene flow and geographical distance was mainly attributable to the landraces Sulkhania and Gowalda. In these villages, only few farmers nowadays grow the landrace, and in Sulkhania, for example, only one farmer had saved the original seed and redistributed it to other farmers of his own and other nearby villages. The reasons why the popularity of these two landraces had decreased were susceptibility to the parasitic weed striga [Striga asiatica (L.) Kuntze] and higher labor requirements compared with improved cultivars (Christinck, 2002).

The Dhodsar landraces ELR28 and ELR29 and the Sulkhania landraces ELR32 and ELR33 demonstrate that populations from the same village can be almost genetically identical even in eastern Rajasthan. Regular interchange of seed within a village, in addition to pollen flight across fields, may explain the revealed molecular similarity. Appa Rao et al. (1986) reported that farmers in eastern Rajasthan were able to maintain certain pearl millet landrace types through geographical isolation. The present cluster analysis and the AMOVA revealed that the original landrace diverged from the introduced versions of the same name-in every case. This is in agreement with farmers' perceptions that landraces undergo change if grown outside the village of origin for more than 2 to $3 \mathrm{yr}$.

Farmers who grew introduced pearl millet landraces practiced panicle selection with the aim to maintain the typical characteristics of the original cultivar (Christinck, 2002). This corroborates with results of Louette and Smale (2000), who showed that ear selection performed by Mexican farmers in maize was a successful method for maintaining a cultivar's phenotype for seed characteristics.

\section{Implications for Genetic Resources Management in Rajasthan}

Because of frequent drought in western Rajasthan, farmers must acquire their seed from other villages within the region. A preferred source are those farmers with a reputation for quality seed, who have an increasing tendency to use improved cultivars for introgression into their landrace seed stocks. The seed system analysis revealed a specific need for preserving the original western Rajasthan landrace type, for the specific benefit of poor farmers, farming mostly poor quality land (Christinck, 2002). The pearl millet mating system in conjunction with farmers' seed management and regional exchange activities has led to regionally similar but highly heterogeneous populations, as reflected in the results of the AFLP analysis. The analysis also shows that the introgression of improved cultivar material affects the genetic composition of the landraces. The low inter- and high intra-population diversity of the landraces suggests that populations managed on farm could form the basis of in situ maintenance projects for pearl millet landraces in western Rajasthan. The marker analysis indicated diversifying selection to be weak in western Rajasthan.

In situ measures could focus on maintaining farmer populations of a small number of sites, those sites where improved cultivars are absent or grown in isolation. Farmers' management would ensure a continuing high degree of heterogeneity and adaptation. The identification of suitable sites and germplasm should be performed in close collaboration with the farmers. On the other hand, populations diversified through improvedcultivar introgression could generate source populations ideal for the development of cultivars suited to the semiarid regions of India.

Another key element of resource management would be to develop strategies for seed dissemination. This would ensure seed availability in times of drought, thus proactively avoiding a situation where farmers are forced to switch to an improved cultivar poorly adapted to their environment. Such distribution networks for landrace seed should address families short on resources, for pure landrace seed is of particular importance to these households (Christinck, 2002). As demand for seed of the western Rajasthan landrace is steady and high, this could become commercially viable.

In eastern Rajasthan, the uniqueness of landrace types was shown to be linked to specific village situations, i.e., it can only be maintained within the village. 
The molecular marker study supported farmers' claims that they maintain individual landraces types. On the basis of this information, future in situ conservation projects for eastern Rajasthan should focus on the maintenance of specific landrace types and should be centered on villages renowned for their specific landrace type. Any project should be performed in close collaboration with the farmers, as they play an integral role in the region's seed network. Specific landraces could be propagated amongst farmers via the traditional seed system or via the activities of extension workers, e.g., demonstration plots that present different landrace types, or other modern tools for dissemination of information. Population improvement methods aimed at increased tolerance against biotic stresses such as striga could be included. Conservation strategies should be concentrated on those landraces that are in a risk of being lost in spite of their unique characteristics.

\section{CONCLUSIONS}

This study demonstrates the usefulness of combining population genetics with participatory socioeconomic research tools. Only the combined analysis of farmers' knowledge, their seed management practices, and the effects of those practices on the genetic structures of populations will lead to a satisfactory understanding of how local seed systems determine crop diversity. The results obtained by this research help identify the main forces that determine genetic diversity, and indicates how they could be strengthened and effectively used for sustainable conservation and crop improvement. The research results demonstrate how the activities of farmers are embedded into their knowledge and social relations, and focus on the farming communities in their active role of creating and using biological diversity. Thus, the approach is practical for investigating the staple food crops of marginal environments, especially in socially diverse regions such as Rajasthan, India.

\section{ACKNOWLEDGMENTS}

The authors are very grateful to: the farmers of Rajasthan for their participation and seed contributions; Dr. S. Sivaramakrishnan for supervising the preparation of plant material for DNA analysis; Dr. H.K. Parzies, Dr. P.J. Bramel, Dr. C.T. Hash, and Dr. O.P. Yadav for their support and advice; and to Mr. T. McGowan for his helpful suggestions and revision of the English.

\section{REFERENCES}

Allard, R.W., and A.D. Bradshaw. 1964. Implications of genotypeenvironment interactions in applied plant breeding. Crop Sci. 4:503-507.

Appa Rao, S., M.H. Mengesha, K.L. Vyas, and C. Rajagopal Reddy. 1986. Evaluation of pearl millet germplasm from Rajasthan. Indian J. Agric. Sci. 56:4-9.

Barrett, B.A., and K.K. Kidwell. 1998. AFLP-based genetic diversity assessment among wheat cultivars from the Pacific Northwest. Crop Sci. 38:1261-1271.

Bellon, M.R., and S.B. Brush. 1994. Keepers of maize in Chiapas. Mexico. Econ. Bot. 48:196-209.

Brown, A.H.D. 2000. The genetic structure of crop landraces and the challenge to conserve them in situ on farms. p. 29-48. In S.B. Brush (ed.) Genes in the field: On-farm conservation of crop diversity. International Development Research Center and International Plant Genetic Resources Institute. Lewis Publishers, U.S.A.

Brush, S.B. 1991. A farmer-based approach to conserving crop germplasm. Econ. Bot. 45:153-165.

Busso, C.S., K.M. Devos, G.Ross, M. Mortimore, W.M. Adams, M.J. Ambrose, Sharon Alldrick, and M.D. Gale. 2000. Genetic diversity within and among landraces of pearl millet (Pennisetum glaucum) under farmer management in West Africa. Genet. Resour. Crop Evol. 47:561-568.

Burton, G.W. 1974. Factors affecting pollen movement and natural outcrossing in pearl millet. Crop Sci. 14:802-805.

Chouhan, T.S. (ed.). 1993. Natural and Human Resources of Rajasthan. Scientific Publisher, Jodhpur.

Christinck, A., K. vom Brocke, K.G. Kshirsagar, E. Weltzien, and P.J. Bramel-Cox. 2000. Participatory methods for collecting germplasm: Experiences with farmers in Rajasthan, India. Plant Genet. Resour. Newsl. 121:1-9.

Christinck, A. 2002. "This seed is like ourselves"- A case study from Rajasthan, India on the social aspects of biodiversity and farmers' management of pearl millet seed. Margraf Verlag, Weikersheim, Germany.

Excoffier, L., P.E. Smouse, and J.M. Quattro. 1992. Analysis of molecular variance inferred from metric distances among DNA haplotypes: Application to human mitochondrial DNA restriction data. Genetics 131:479-491.

Hawtin, G., M. Iwanaga, and T. Hodgkin. 1997. Genetic resources in breeding for adaptation. p. 277-289. In P.M.A. Tigerstedt (ed.) Adaptation in plant breeding. Kluwer Academic Publishers, the Netherlands.

Karp, A., P.G. Isaak, and D.S. Ingram (ed.). 1998. Molecular tools for screening biodiversity. Chapman and Hall, London.

Kelley, T.G., P. Parthasarathy, E. Weltzien R., and M.L. Purohit. 1996. Adoption of improved cultivars of pearl millet in an arid environment: straw yield considerations in western Rajasthan. Exp. Agric. 32:161-171.

Kremer, A., R.J. Petit, and O. Pons. 1998. Measures of polymorphism within and among populations. In A. Karp, P.G. Isaak and D.S. Ingram (ed.) Molecular tools for screening biodiversity. Chapman and Hall, London.

Leuck, D.B., and G.W. Burton. 1966. Pollination of pearl millet by insects. J. Econ. Entomol. 59:1308-1309.

Louette, D., A. Charrier, and J. Berthaud. 1997. In situ conservation of maize in Mexico: genetic diversity and maize seed management in a traditional community. Econ. Bot. 51:20-38.

Louette, D., and M. Smale. 2000. Farmers' seed selection practices and traditional maize varieties in Cuzalapa, Mexico. Euphytica 113:25-41.

Maughan, P.J., M.A. Saghai Maroof, and G.R. Buss. 1996. Amplified fragment polymorphism (AFLP) in soybean: species diversity, inheritance, and near-isogenic line analysis. Theor. Appl. Genet. 93:392-401.

Nevo, E., B. Baum, A. Beiles, and D.A. Johnson. 1998. Ecological correlates of RAPD DNA diversity of wild barley, Hordeum spontaneum, in the Fertile Crescent. Genet. Resour. Crop Evol. 45:151159.

Ollitrault, P., J.L. Noyer. J. Chantereau, and J.C. Glaszmann. 1997. Structure génétique et dynamique des vartiétés traditionnelles de sorgho au Burkina Faso. p. 231-240. In Actes du colloque Gestion des Ressources des Plantes en Afrique des Savanes, 24-28 February 1997. Bamako, Mali. IER-BRG-Solagral.

Parzies, H.K. 2000. Investigation of the population structure of barley landraces (Hordeum vulgare L.) from different eco-geographical environments in Syria. PhD Thesis, University of Edinburgh.

Rohlf, F.J. 1993. NTSYS-pc: Numerical taxonomy and multivariate analysis system. Exeter Publishers, Setauket. NY.

Schneider, S., J.M. Kueffer, D. Roessli, and L. Excoffier. 1997. Arlequin ver. 1.1: A software for population genetic data analysis. Genetics and Biometry Laboratory, University of Geneva, Geneva, Switzerland.

Schönhuth, M., and U. Kievelitz. 1994. Participatory learning approaches-rapid rural appraisal, participatory appraisal, an introductory guide. Deutsche Gesellschaft für Technische Zusammen- 
arbeit (GTZ) GmbH (ed.). TZ-Verlagsgesellschaft, Rossdorf, Germany.

Slatkin, M., and N.H. Barton. 1989. A comparison of three indirect methods for estimating average levels of gene flow. Evolution 43: $1349-1369$.

Slatkin, M. 1993. Isolation by distance in equilibrium and non-equilibrium populations. Evolution 47:264-279.

Sperling, L., M.E. Loevinsohn, and B. Ntabomvuras. 1993. Rethinking the farmer's role in plant breeding: local bean experts and on station selection in Rwanda. Exp. Agric. 29:509-519.

Tostain, S. 1994. Isozymic classification of pearl millet (Pennisetum glaucum, Poaceae) landraces from Niger (West Africa). Plant Syst. Evol. 193:81-93.

Tripp, R., and S. Pal. 1998. Information exchange in commercial seed markets in Rajasthan. ODI Network paper No. 83, London.

Vom Brocke, K., T. Presterl, A. Christinck, E. Weltzien, and H.H. Geiger. 2002. Farmers' seed management practices open up new base populations for pearl millet breeding in a semi-arid zone of India. Plant Breed. 121:39-45.
Vos, P., R. Hogers, M. Reijans, T. van Lee, M. Hornes, A. Frijters, J. Pot, J. Peleman, M. Kuiper, and M. Zabeau. 1995. AFLP: a new technique for DNA fingerprinting. Nucleic Acids Res. 23:44074414.

Vyas, K.L. 1987. Genetic divergence in landraces of pearl millet in Rajasthan. p. 291. In J.R. Witcombe and S.R. Beckerman (ed.) Proceedings of the International Pearl Millet Workshop, 7-11 April 1986, ICRISAT Centre, India, Patancheru, A.P. 502 324, India.

Weltzien, R.E., M.L. Whitaker, H.F.W. Rattunde, M. Dhamotharan, and M.M. Anders. 1998. Participatory approaches in pearl millet breeding. p. 143-170. In J.R Witcombe, D.S. Virk and J. Farrington (ed.) Seeds of choice: Making the most of new varieties for small farmers. Oxford and IBH Publishing Co. Pvt Ltd, Delhi, India.

Wright, S. 1951. The genetical structure of populations. Ann. Eugen. 15:323-354.

Yeh, F.C., R.-C. Yang, and T.B.J. Boyle. 1999. Popgene version 1.31. Microsoft Windows-based freeware for population genetic analysis. Molecular Biology and Biotechnology Centre, University of Alberta, Canada and Centre for International Forestry Research. 